\title{
Anatomical Study of Pronator Teres Muscle Innervation and Clinical Significance in Nerve Transfer
}

\author{
Estudio Anatómico de la Inervación del Músculo Pronador Redondo \\ y Significado Clínico en la Transferencia Nerviosa
}


Rodrigo Guerra Sabongi ${ }^{3}$; Luca Martinez ${ }^{4}$; Kelson Koiti Ogata ${ }^{4}$ \& Eduardo Baldy de Sousa Boni ${ }^{4}$
\end{abstract}

CAETANO, E. B.; VIEIRA, L A.; SABONGI NETO, J. J. ; CAETANO, M. B. F.; SABONGI, R. G.; MARTINEZ, L.; OGATA, K. K. \& BONI, E. B. S. Anatomical study of pronator teres muscle innervation and clinical significance in nerve transfer. Int. J. Morphol., 36(4):1500-1508, 2018.

SUMMARY: The anatomical relationship of the median nerve and its innervation pattern are variable and may have direct implications in surgical procedures such as distal nerve transfers. The objective of this study was to evaluate the anatomical variations of pronator teres muscle (PTM) innervation and its clinical significance in nerve transfers. Data were collected regarding the number of median nerve branches, site of their origin, contribution with branches of other muscles and the possibility of transferring expendable branches of PTM to the anterior interosseous nerve (AIN) and radial nerve. The most common origin of the branches was proximal to the humeral intercondylar line. The presence of only one PTM branch was identified in 9 limbs, in which 6 was exclusive for this muscle. The majority of specimens presented more than one branch to the PTM, with two branches in 19, although only 6 of these did not share branches with other muscles. The proximal branch of the PTM was long enough to be transferred to the AIN in 23 limbs and branches of the radial nerve in all. These transfers were possible even during the forearm prone-supination and flexion-extension of the elbow. The use of the PTM branch may be considered for transfers in C7-T1 root injuries of the brachial plexus, with care regarding the availability of multiple PTM branches and tension to the AIN and radial nerve branches.

KEY WORDS: Peripheral nerve injury; Nerve transfer; Median nerve; Anatomic variations.

\section{INTRODUCTION}

The usually described anatomical pattern of the pronator teres muscle (PTM) is a two-headed muscle, with a humeral head that extends from the medial epicondyle of humerus and surroundings, and an ulnar head that originates from the coronoid process of the ulna. These portions connect in a single insertion, contouring the radial diaphysis (Paturet, 1954; Rouvière \& Delmas, 1984). The median nerve has an intimal relation with the PTM, located between its two heads. The absence of the ulnar head has been variable in different studies (Nebot-Cegarra et al., 1991; Pires \& Andrade, 2008; Caetano et al., 2017), as well as the relation with the median nerve and the innervation pattern (Sunderland, 1978; Fuss \& Wurzl, 1990; Gunther et al., 1992; Canovas et al., 1998; Chantelot et al., 1999; Tung \& Mackinnon, 2001). Although the PTM is exclusively innervated by the median nerve, the site, number of fascicles and simultaneous innervation of other muscles is debatable (Sunderland; Fuss \& Wurzl; Gunther et al.; Canovas et al.; Chantelot et al.; Tung \& Mackinnon). Usually, it shares branches with the flexor carpus radialis (FCR), palmaris longus (PL), flexor digitorum superficialis (FDS) and anterior interosseous nerve (AIN).

In cases which nerve repair through suture of nerve stumps is not possible, nerve grafts remain the first option of most surgeons (Hsiao et al., 2009; Bertelli \& Ghizoni, 2010; Tubbs et al., 2011; García-López et al., 2014). However, there are injuries where primary repair is not feasible and grafting does not provide satisfactory results such as proximal nerve lesions, large gaps, nerve palsies or neuritis in which no proximal healthy nerve is present. To circumvent these problems, nerve transfers provide an

\footnotetext{
${ }^{1}$ Department of Surgery of the Faculty of Medical Sciences and Health, Pontifical Catholic University of São Paulo - Sorocaba (SP), Brazil.

${ }^{2}$ Service of Surgery of the Hand - Conjunto Hospitalar de Sorocaba - Sorocaba (SP), Brazil.

${ }^{3}$ Resident of Orthopedics of the Faculty of Medicine, Federal University of São Paulo - São Paulo (SP), Brazil.

${ }^{4}$ Resident of Orthopedics of the Faculty of Medical Sciences and Health, Pontifical Catholic University of São Paulo - Sorocaba (SP), Brazil.
} 
effective alternative surgical option (Tung \& Mackinnon; Li et al., 2016; Mackinnon \& Novak, 1999; Hsiao et al.). Motor function recovery after nerve repair depends on a sufficient number of axons regeneration to reach the target muscle, and this has to occur prior to the neuromuscular junction degeneration (Li et al.; Mackinnon \& Novak; Hsiao et al.; Bertelli \& Ghizoni; Tubbs et al.; García-López et al.). High nerve injuries and the presence of a gap among nerve stumps may delay the regenerating process to a point where motor plates are resistant to reinnervation. The concept of nerve transfers to manage brachial plexus injuries is not new, however distal transfers are a recent innovation (Li et al.; Mackinnon \& Novak). Distal donor nerves have several advantages such as proximity to the recipient motor plates, elimination of injury area and assurance of a source of axons from a donor nerve. Transferring a nerve distally and close to the target muscle mitigates the extended time of regeneration, ultimately converting a proximal level lesion in a distal injury (Mackinnon \& Novak; Hsiao et al.; Bertelli \& Ghizoni; Tubbs et al.; García-López et al.; Li et al.). García-López et al. reported the advantages of the nerve transfers over tendon transfers, for example: maintaining the original tendon trajectory, minor surgical exposure, no need of prior passive wrist mobility, individual thumb extension without a separate transfer and a more natural fingers independent movement. The drawback of nerve transfers is related to the waiting time for the nerve regeneration process.

The objective of this study was to evaluate the anatomical variations of PTM innervation and its clinical implications in nerve transfers, particularly in radicular avulsions of C7-T1 brachial plexus injury. In these cases, radial nerve branches and AIN may be paralyzed.

\section{MATERIAL AND METHOD}

The study was based on the dissection of 30 limbs of 15 male anatomical specimens, prepared with intra-arterial glycerin and formalin $10 \%$ injection and approved by the Ethical Commission. (n.2.207.267). Dissections were performed with a $2.5 x$ loupe and the limbs were positioned with elbow extension, neutral wrist position and forearm in pronation. No specimen presented evidence of deformities, neither scars from previous trauma or procedures. Skin and fascia from the flexor surface of the distal arm, forearm and wrist were removed. The median nerve was identified in the arm and dissected distally after sectioning the bicipital aponeurosis. The ulnar head of the PTM was detached distally and retracted while the FCR and PL tendons were sectioned in the distal third after identification of the nerve branches. Following longitudinal separation of the FDS and its fibrous arch, the AIN was identified and followed distally, while branches to the flexor digitorum profundus muscle (FDP), flexor pollicis longus muscle (FPL) and pronator quadratus muscle (PQ) were dissected and marked. Measures of the forearm length were performed tracing a line from the midpoint of the intercondylar line to the midpoint of the radio-ulnar styloid line. The origin of each median nerve branch was measured from the humeral intercondylar line (HIL). The PTM branch was sectioned distally close to the muscle fibers and directed to the AIN origin. Afterwards, the branch was tunneled laterally and deep to the biceps muscle to reach the radial nerve at the cubital fossa. These transfers were evaluated by the feasibility, tension of the suture site and relation with forearm and elbow movement. With a digital caliper, we measured the branches of the pronator teres muscle (PTM), anterior interosseous nerve (AIN), extensor carpi radialis longus muscle (ECRL), extensor carpi radialis brevis muscle (ECRB), and posterior interosseous nerve (PIN). The AIN was measured soon after detaching from the median nerve, before its branching in FDP, FPL and PQ.

\section{RESULTS}

The median forearm length was $26.2( \pm 2.7 \mathrm{~cm})$. The median nerve innervated the PTM exclusively in all forearms. The first branch of the median nerve was to the PTM in all specimens with the exception of one that presented multiple anatomical variations in which the AIN received the first branch (Fig. 1A). Another atypical case was the same level origin of the PTM and the FDS branches (Fig. 1B). The site of PTM branch origin was situated in an interval, ranging $6.8 \mathrm{~cm}$ proximal and $2.8 \mathrm{~cm}$ distal to the HIL, being $17(56.6 \%)$ limbs proximal (Fig. 2A), 8 (26.6\%) distal (Fig. $3 \mathrm{~A})$ and $5(16 \%)$ at this anatomical landmark (Fig. 2B). The presence of only one median nerve branch destined for PTM was identified in 9 specimens (30\%), in which $6(20 \%)$ does not share with other muscles (Fig. 3B), while in $2(6.6 \%)$, the branch also innervated the FCR (Fig. 4A) and in $1(3.3 \%)$ shares with the FCR, FDS and PL (Fig. 4B).

High origin of the humeral head of the PTM was registered in $3(10 \%)$ specimens $(2.8-3.5 \mathrm{~cm}$ proximal to the HIL), where the first branch of the median nerve devised $4.8 \mathrm{~cm}, 5.5 \mathrm{~cm}$ and $6.8 \mathrm{~cm}$ proximal to the HIL. In 21 (70 $\%)$ limbs, there were more than one branch to the PTM, with two branches present in $19(64 \%)$ specimens, where the first branch was more proximal, longer and exclusive to the PTM in all of them. The mean length of the proximal branch was $4.0 \mathrm{~cm}$ (ranging from $3.0-5.2 \mathrm{~cm}$ ). A second exclusive branch to the PTM was identified in $5(16.6 \%)$ 

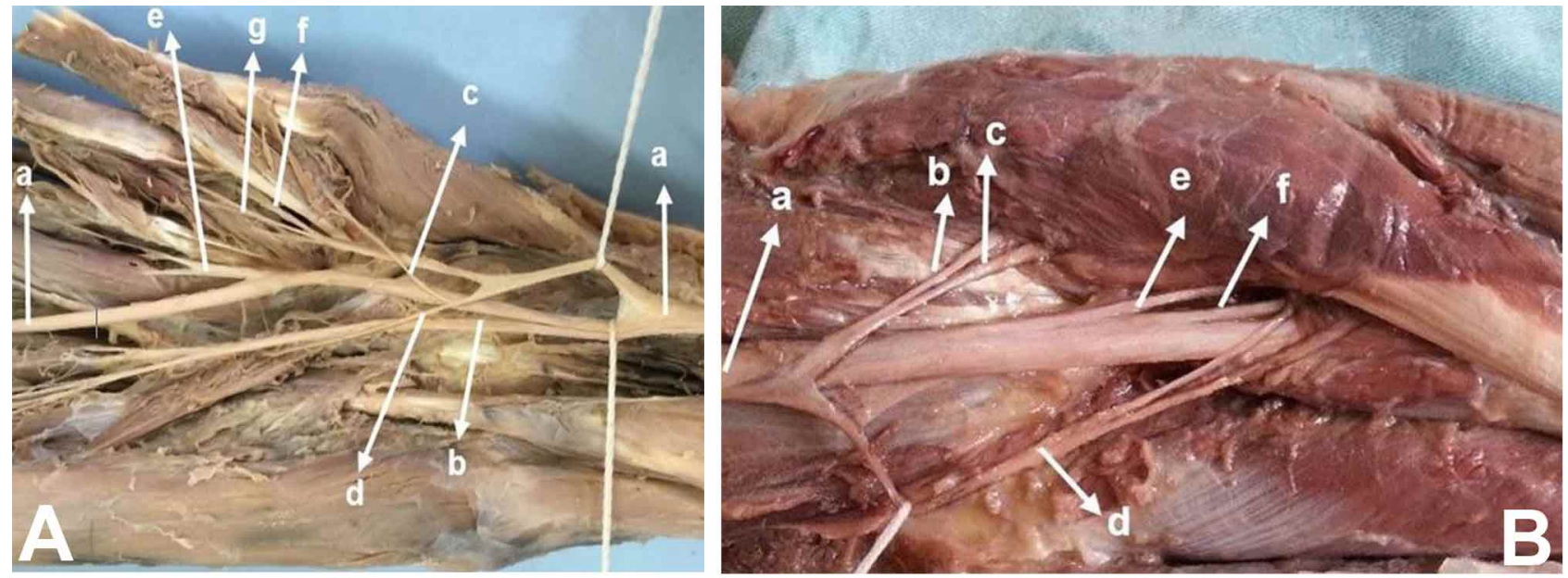

Fig. 1A. (a) Median Nerve; (b) Anterior interosseous nerve; (c) Pronator teres branch (Humeral head); (d) Pronator teres branch (ulnar head); (e) Flexor digitorum superficialis branch; (f) Palmaris longus branch; (g) Flexor carpi radialis branch. B. (a) Median nerve; (b) Pronator teres branch; (c) Palmaris longus branch; (d) Flexor digitorum superficialis branch; (e) Flexor carpi radialis branch; (f) Anterior interosseous nerve.
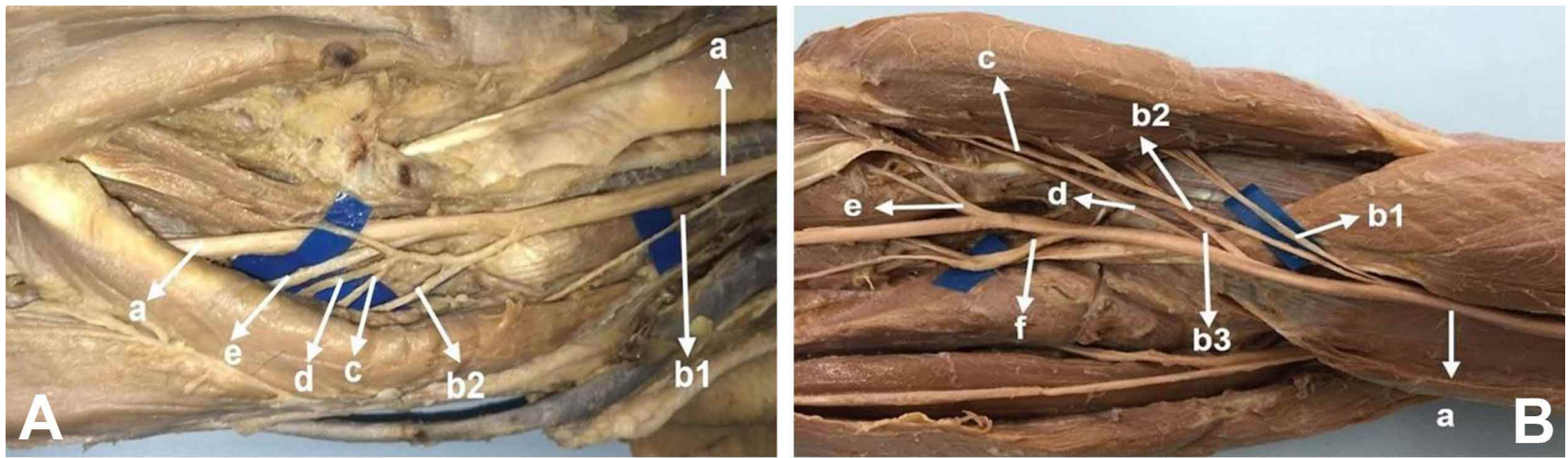

Fig. 2A. (a) Median Nerve; (b1) Pronator Teres First Branch; (b2) Pronator Teres Second Branch; (c) Palmaris Longus Branch; (d) Flexor Carpi Radialis Branch; (e) Anterior Interosseous Nerve Branch. B. (a) Median Nerve; (b1) Pronator Teres First Branch; (b2) Pronator Teres Second Branch; (b3) Pronator Teres Third Branch; (c) Palmaris Longus Branch; (d) Flexor Carpi Radialis Branch; (e) Flexor Digitorum Superficialis Branch; (f) Anterior Interosseous Nerve.
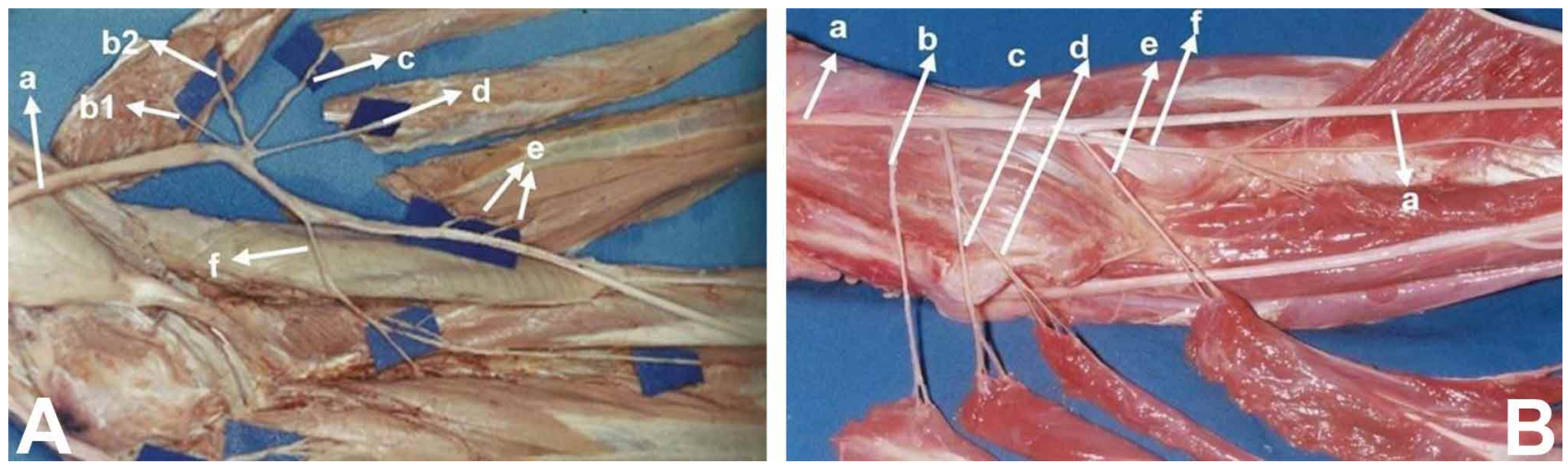

Fig. 3A. (a) Median Nerve; (b1) Pronator Teres First Branch; (b2) Pronator Teres Second Branch; (c) Palmaris Longus Branch; (d) Flexor Carpi Radialis Branch; (e) Flexor Digitorum Superficialis Branch; (f) Anterior Interosseous Nerve B. (a) Median Nerve; (b) Pronator Teres Branch; (c) Flexor Carpi Radialis Branch; (d) Palmaris Longus Branch; (e) Flexor Digitorum Superficialis Branch; (f) Anterior Interosseous Nerve. 

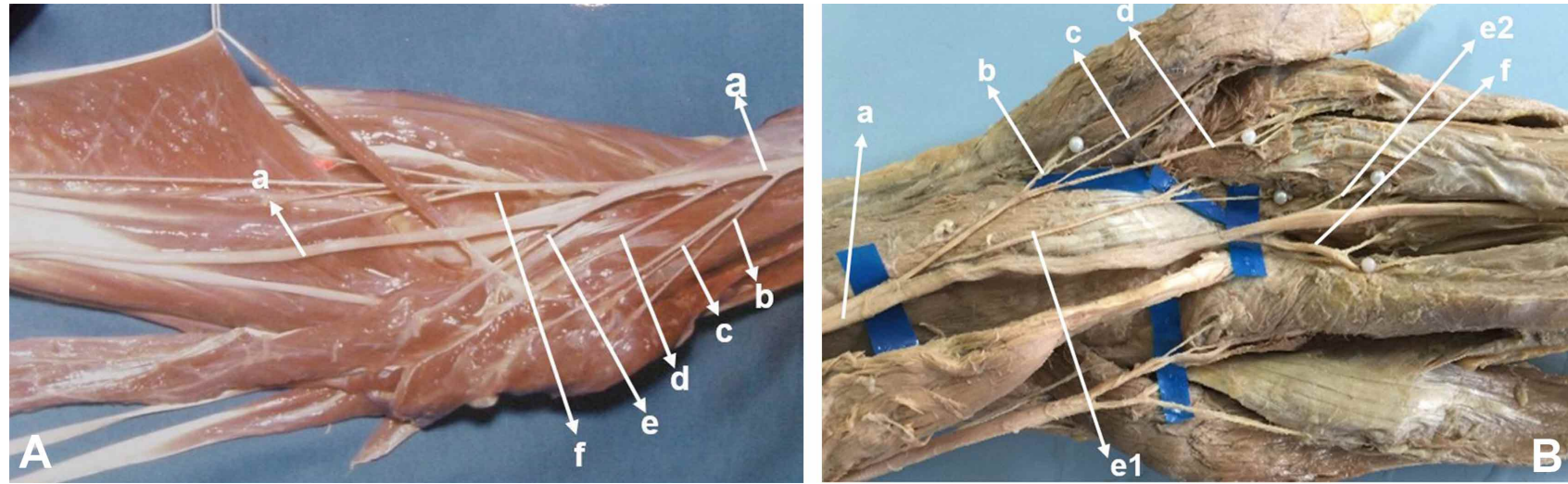

Fig. 4A. (a) Median Nerve; (b) Pronator Teres Branch; (c) Flexor Carpi Radialis Branch; (d) Palmaris Longus Branch; (e) Flexor Digitorum Superficialis Branch; (f) Anterior Interosseous Nerve. B. (a) Median Nerve; (b) Pronator Teres Branch; (c) Palmaris Longus Branch; (d) Flexor Carpi Radialis Branch; (e1) Flexor Digitorum Superficialis First Branch; (e2) Flexor Digitorum Superficialis Second Branch; (f) Anterior Interosseous Nerve.
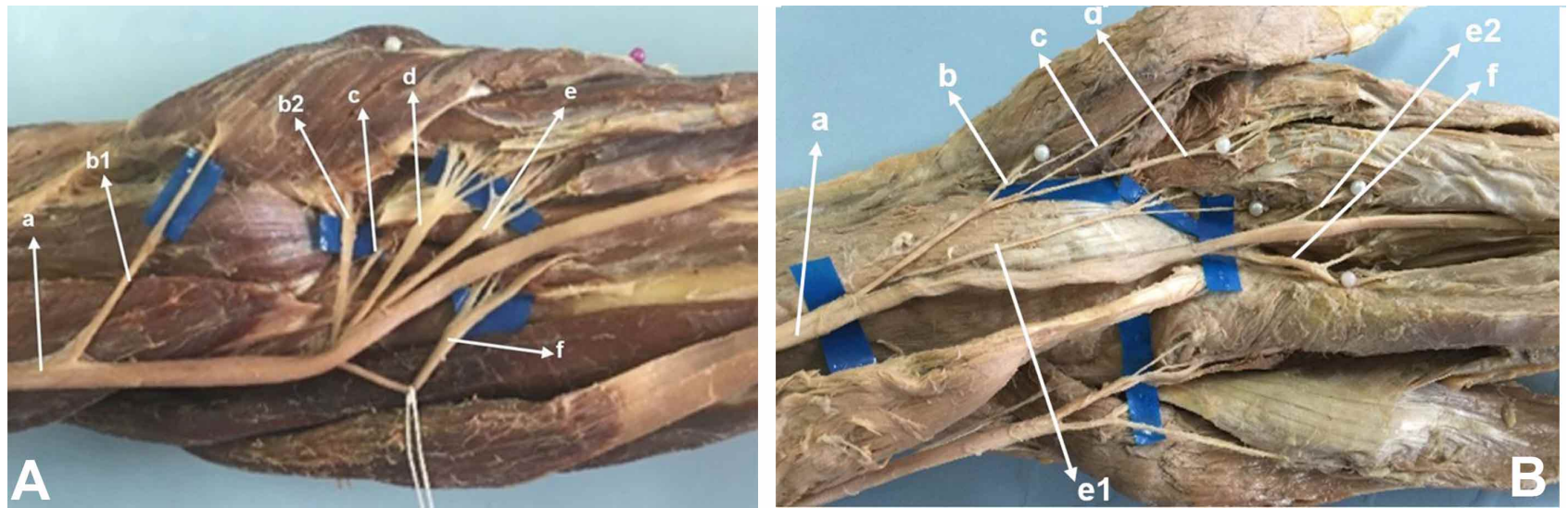

Fig. 5A. (a) Median Nerve; (b1) Pronator Teres First Branch; (b2) Pronator Teres Second Branch; (c) Palmaris Longus Branch; (d) Flexor Carpi Radialis Branch; (e) Flexor Digitorum Superficialis Branch; (f) Anterior Interosseous Nerve B. (a) Median Nerve; (b1) Pronator Teres First Branch; (b2) Pronator Teres Second Branch; (c) Flexor Carpi Radialis Branch; (d) Palmaris Longus Branch; (e) Flexor Digitorum Superficialis Branch; (f) Anterior Interosseous Nerve.
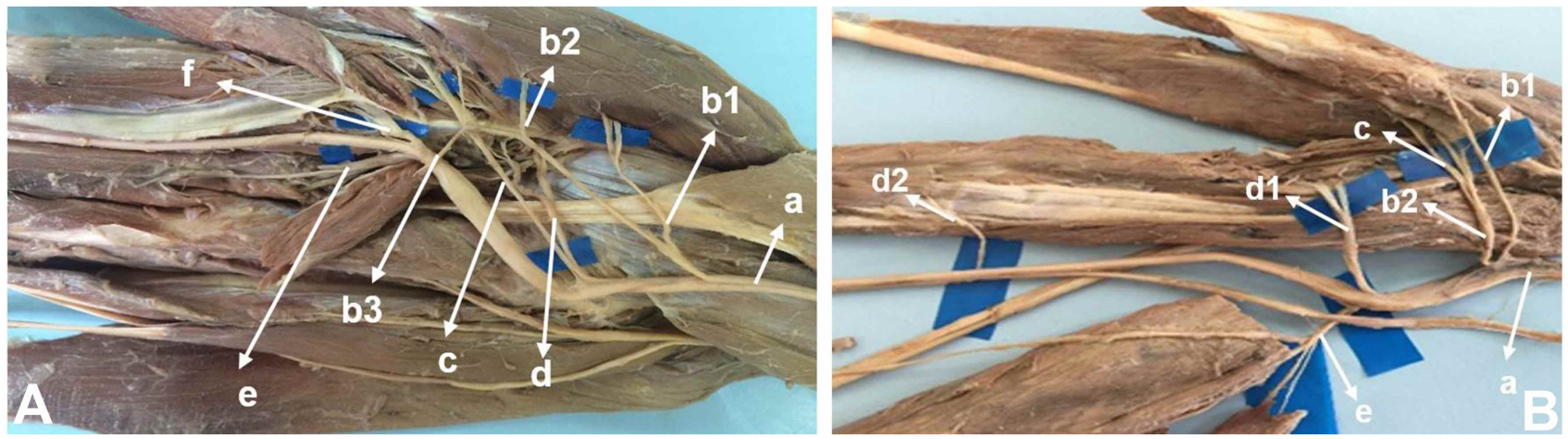

Fig. 6A. (a) Median Nerve; (b1) Pronator Teres First Branch; (b2) Pronator Teres Second Branch; (b3) Pronator Teres Branch to ulnar head (c) Flexor Carpi Radialis Branch; (d) Palmaris Longus Branch; (e) Anterior Interosseous; (f) Flexor Digitorum Superficialis Branch B. (a) Median Nerve; (b1) Pronator Teres First Branch; (b2) Pronator Teres Second Branch; (c) Flexor Carpi Radialis Branch; (d1) Flexor Digitorum Superficialis First Branch; (d2) Flexor Digitorum Superficialis Second Branch; (f) Anterior Interosseous Nerve.

cases (Fig. 5B). The PTM shares branch with PL (Fig. 6A) in $4(13.3 \%)$ limbs, while $5(16.6 \%)$ shares branches with
FCR (Fig. 6B), 3 (10\%) with both PL and FCR (Fig. 7A), and $2(6.6 \%)$ with PL, FCR and FDS (Fig. 2A). In 2 (6.6\%) 
specimens, the median nerve originated three branches, the first two innervating exclusively the PTM and the third shares branch with FCR (Fig. 7B). The absence of the PL was registered in $4(13.3 \%)$ cases (Fig. 6B) and the ulnar head of the PTM in 6 cases $(20 \%)$ (Fig. 3B). In the $24(80 \%)$ limbs that was present, $18(60 \%)$ were innervated by an
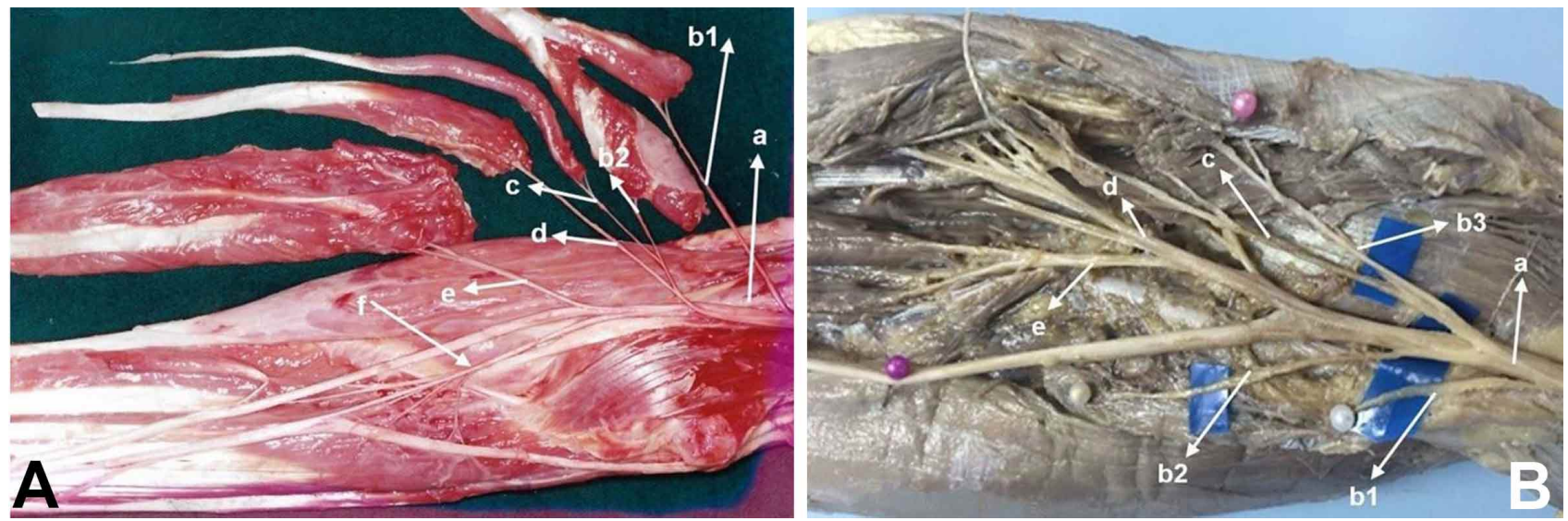

Fig. 7A. (a) Median Nerve; (b1) Pronator Teres Ulnar Head Branch; (b2) Pronator Teres Humeral Head Branch; (c) Palmaris Longus Branch; (d) Flexor Carpi Radialis Branch; (e) Flexor Digitorum Superficialis Branch; (f) Anterior Interosseous Nerve B. (a) Median Nerve; (b1) Pronator Teres First Branch; (b2) Pronator Teres Second Branch; (b3) Pronator Teres Third Branch; (c) Flexor Carpi Radialis Branch; (d) Flexor Digitorum Superficialis First Branch; (f) Anterior Interosseous Nerve.
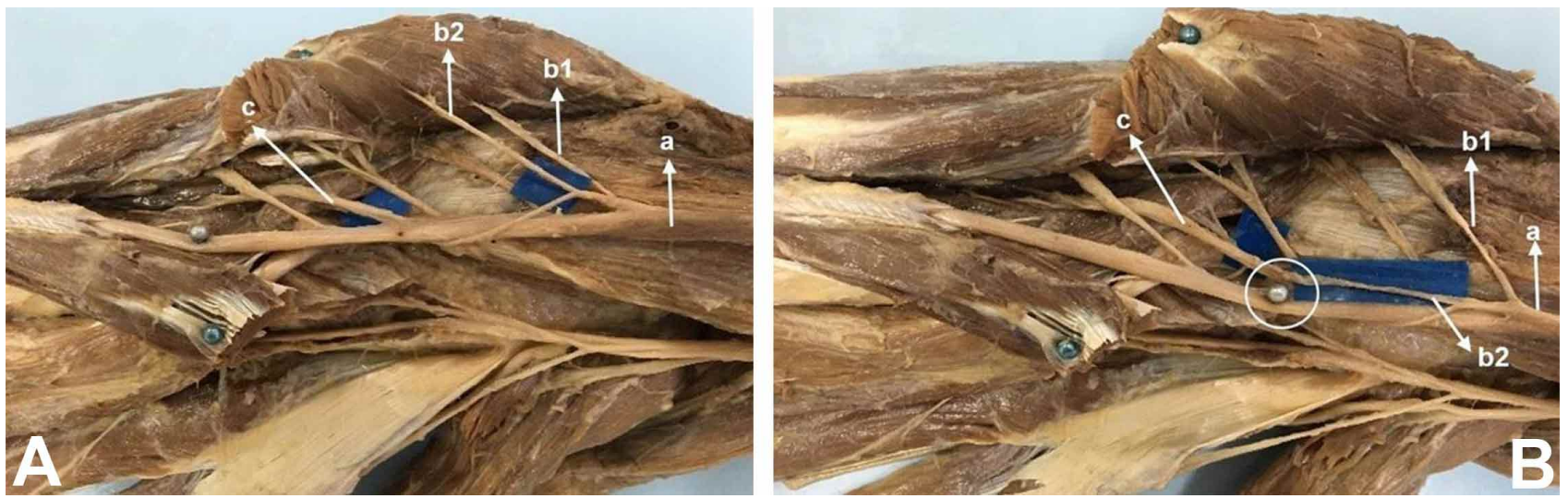

Fig. 8A. (a) Median Nerve; (b1) Pronator Teres Humeral Head Branch First Branch; (b2) Pronator Teres Humeral Head Second Branch; (c) Anterior Interosseous Nerve (d) Pronator Teres Ulnar Head Branch B. (a) Median Nerve; (b1) Pronator Teres Humeral Head First Branch, (b2) Pronator Teres Humeral Head Second Branch; (c) Transfer to Anterior Interosseous Nerve.


Fig. 9A. (a) Median Nerve; (b1) Pronator Teres First Branch; (b2) Pronator Teres Second Branch B. (a) Pronator Teres First Branch; (b) Pronator Teres Second Branch transfer to: (c) Posterior interosseous Nerve; (d) Extensor Carpi Radialis Brevis; (e) Extensor Carpi Radialis Longus. 
exclusive branch for the muscular head (Figs. 7A and 8B). The ulnar head from the PTM was supplied by the first branch of the median nerve in 7 limbs, second branch in 10 and third branch in 1 (Table I).

An appropriate branch to the PTM was selected for transfer (generally the most proximal branch because it had more length), was cut at its entrance into the PTM, and was moved laterally. The AIN was cut at its origin from median nerve, and the nerve to the ECRL, ECRB and PIN was also cut at its origin from the radial nerve and medially displaced towards the median nerve branches to the PTM. This was done to verify if the nerve stumps could be placed in direct contact without tension, thus mimicking in cadaver limbs the clinical procedure in vivo.

Table I. Nerve measurements.

\begin{tabular}{lccc}
\hline & Number of branches & Mean nerve width $(\mathrm{mm})$ & Mean nerve length (mm) \\
\hline PTM branch & $1-3(\mathrm{n}: 30)$ & $1.5 \pm 0.6(\mathrm{n}: 14)$ & $4.0 \pm 1.2(\mathrm{n}: 14)$ \\
AIN & $1(\mathrm{n}: 30)$ & $1.7 \pm 0.5(\mathrm{n}: 14)$ & $3.5 \pm 1.0(\mathrm{n}: 14)$ \\
AIN branch to PQ & $1(\mathrm{n}: 30)$ & $1.0 \pm 0.4(\mathrm{n}: 14)$ & $9.5 \pm 2.5(\mathrm{n}: 14)$ \\
PIN & $1(\mathrm{n}: 30)$ & $3.0 \pm 0.5(\mathrm{n}: 30)$ & $6.5 \pm 2.5(\mathrm{n}: 30)$ \\
ERLC branches & $1-2(\mathrm{n}: 30)$ & $1.5 \pm 0.6(\mathrm{n}: 30)$ & $2.5 \pm 1.0(\mathrm{n}: 30)$ \\
ERCC & $1(\mathrm{n}: 30)$ & $1.4 \pm 0.7(\mathrm{n}: 30)$ & $5.5 \pm 2.5(\mathrm{n}: 30)$ \\
\hline
\end{tabular}

\section{DISCUSSION}

Anatomy textbooks usually describe the classic median nerve distribution in the forearm: two branches (superior and inferior) to the PTM, one common trunk to the FCR and PL, and one branch to the FDS (Paturet; Rouvière \& Delmas). Recent studies revealed considerable variations of this pattern in several anatomical series (Sunderland; Fuss \& Wurzl; Gunther et al.; Canovas et al.; Chantelot et al.; Tung \& Mackinnon). Our results are in accordance with several authors reiterating that the first branch of the median nerve was to the PTM in the majority of cases (Sunderland; Fuss \& Wurzl; Gunther et al.; Canovas et al.; Chantelot et al.; Tung \& Mackinnon). In just one limb with atypical nerve distribution, the first branch originated the AIN. Chantelot et al. in a 50 limbs anatomical study, reported that only in two limbs the first branch was not destined to the PTM. However, there are controversies regarding the site where branching occurs in relation to the HIL. The reports of the authors about the nerve relation to HIL, numbers of branches and the sharing with other nerves were displayed in Table II. These anatomical details are not an absolute clinical need in preparation for a nerve transfer to restore the extension of the fingers, whereas their knowledge facilitates the identification of these nervous branches. Sunderland described 20 cases in which median nerve branches appeared in a segment $7 \mathrm{~cm}$ proximal and $2.3 \mathrm{~cm}$ distal to the HIL ( $40 \%$ proximal, $20 \%$ at the HIL and $40 \%$ distal). Alves et al. (2004) dissected 18 limbs and identified that $93.3 \%$ of these branches were formed proximally and $6.7 \%$ distal to this landmark. Fuss \& Wurzl stated that branching happened in a segment $3.5 \mathrm{~cm}$ proximal and 5.5 $\mathrm{cm}$ distal to the HIL in 50 dissected limbs, despite not informing the rates of occurrence. Tung \& Mackinnon analyzed PTM innervation in 31 limbs and reported that the most proximal branch of the median nerve originated proximal to the HIL in $23 \%$, whereas in $6.5 \%$ all PTM branches were proximal and $77 \%$ were distal to this landmark. Our study demonstrated intermediate results when compared to Sunderland and Alves et al., since branches to PTM originated between $6.8 \mathrm{~cm}$ proximal and 2.8 distal to the HIL. Gunther et al. reported an interval of $4.5 \mathrm{~cm}$ proximal and $3.5 \mathrm{~cm}$ distal and declared that the first PTM branch was $4 \mathrm{~cm}$ or more proximal to the HIL in cases of high humeral head origin. We once corroborate these findings in $3(10 \%)$ limbs that had more proximal humeral head origin, and the branching occurred $4.8,5.5$ and $6.8 \mathrm{~cm}$ proximal to the HIL.

Regarding the number of PTM median nerve branches, Sunderland registered a single branch in $30 \%$ and two branches in $70 \%$, and the first one always innervating the humeral head. Fuss \& Wurzl also reported the number of PTM branches in 50 limbs, with one in $28 \%$, two in 44 $\%$, three in $20 \%$ and four in $8 \%$ of cases. Gunther et al. found a single branch in $55 \%$ while multiple ramifications happened in $45 \%$. Canovas et al. identified a consistent pattern of one proximal and one distal branch in all 10 dissected limbs. Chantelot et al. recognized more than one PTM branch in $44 \%$ of the 50 limbs analyzed, while Tung \& Mackinnon reported a rate of $73 \%$ multiple branches when dissecting 31 limbs. Yang et al. (2014) informed that all the 30 limbs evaluated had multiple PTM branches. Our results are in accordance with Sunderland, Fuss \& Wurzl and Tung \& Mackinnon, once we registered more than one branch in $70 \%$, two in $64 \%$ and three in $6 \%$ of the limbs analyzed. We 
have not found cases with three branches to the PTM, in contrast to Sunderland and Fuss \& Wurzl which reported more than three branches in $8 \%$. The prevalence of only one branch to the PTM ranged from $27 \%$ to $56 \%$ (Sunderland; Fuss \& Wurzl; Chantelot et al.; Tung \& Mackinnon). Our findings are in agreement with these reports with a single branch identified in $23.3 \%$. As previously described (Fuss \& Wurzl), multiple branches to the PTM have a consistent arrangement: the longer proximal branch penetrates proximally in the muscle, while the shorter distal branch divides before innervating the distal portion of the PTM. Moreover, when the ulnar head was identified, it was innervated by the distal branch. However, we have found that in $75 \%$ (Alves et al.) of cases where the ulnar head was present, there was an isolated branch to this muscle, being the first branch in 7 limbs, the second in 10 and the third in 1 limb.

Regarding the sharing of PTM median nerve branches for innervation of other muscles, there are more controversy in the literature. Sunderland stated that the proximal branch to the PTM had common origin only with the branch to the FCR, while the distal branch had mutual origin with other muscles in $35 \%$ of cases. Gunther et al. reported $95 \%$ of shared fibers innervating other muscles, mainly the FCR, which was found in $80 \%$. Canovas et al. disclosed the proximal branch innervating different muscles in $20 \%$ of the 10 dissected limbs, while the distal branch was shared in 70 $\%$, communicating with the proximal branch, branch to the FCR, FDS and PL. Chantelot et al. identified this shared pattern in $14 \%$, with 3 cases of a common trunk to the PTM, FCR and PL, one case with a trunk to the PTM and FDS and a common trunk to the PTM, FCR, PL and FDS in three limbs. We have found that all dissected limbs presented a proximal branch that was longer and exclusive to the PTM. The second branch innervated the PTM alone in $20 \%$, while $13.3 \%$ was shared with the PL, $16.6 \%$ with the FCR, $13.3 \%$ with the PL and FCR (Fig. 7A), and $6.6 \%$ with the PL, FCR and FDS. In $2(6.6 \%)$ limbs, median nerve originated three branches, with the first two innervating the PTM alone and the third was shared with the FCR. Our findings of only $20 \%$ classical innervation pattern of the PTM with two branches are similar to Chantelot et al. who reported this distribution in $26 \%$, while in $74 \%$ there was some anatomical variation.

When more than one branch to the PTM is present, there is the possibility of a nerve transfer, leaving the PTM partially innervated. We observed that 21 limbs had one branch of PTM expendable, and one of them was long enough to reach AIN without tension or need for intraneural dissection in $73 \%$. This transfer remained free of tension even through full range of movement of the elbow and forearm (Figs. 8A and 8B). Internal neurolysis from distal to proximal with the intention of mobilizing the AIN fascicles, in order to perform a tension free transfer, was necessary in $27 \%$ of the limbs. The first PTM branch of the median nerve had enough length to be transferred to the AIN in $23(76 \%)$ limbs, while they could reach the radial nerve branches to the ECRL, ERCB and PIN distal to branches for the supinator muscle in all members. The AIN was cut at its origin from median nerve, and the nerve to the ECRL, ECRB and PIN was also cut at its origin from the radial nerve and medially displaced towards the median nerve branches to the PTM. The PIN cut depends on each situation and should be decided during the surgical procedure. One of the branches destined for PTM was long enough to be connected to the PIN distal to the emergence of the nerves to the supinator in $12 \mathrm{limbs}$ (Fig. 9A). This fact avoids that donor axons are not wasted in unnecessary reinnervation of the supinator muscle, since supination is preserved by the action of the biceps muscle. In 18 limbs, branches to the supinator were sectioned to allow the PIN to be moved medially to connect to the donor nerve (Fig. 9B). To shorten the axonal regeneration distance, it is desirable to perform nerve coaptation near the target muscle, closest as possible without tension. During range of movement of the elbow and forearm, tension free coalition was observed. This was done to verify if the nerve stumps could be placed in direct contact without tension, thus mimicking in cadaver limbs the clinical procedure in vivo. This procedure leaves PTM partially innervated; however, this anatomical study does not allow us to state that the remaining branches are sufficient to preserve an adequate pronation function of the forearm. The section of the branches to the supinator is advantageous because it favors the direction of the axons from the PTM to be destined only to the extensor of the fingers and the thumb. Pronation is maintained by the action of the biceps muscle and the supinator muscle is not used in tendon transfers. The mean diameter of theproximal branch for PTM was $(1.5 \pm$ 0.6 ), and corresponded to $88 \%$ of the mean diameter of the AIN $(1.7 \pm 0.5)$. The mean diameter of the branches for the ERLC $(1.5 \pm 0.6)$ and ERCC $(1.4 \pm 0.7)$ muscles were relatively compatible, with branch diameter for PTM. However, its diameter corresponded to only $50 \%$ of the diameter of the PIN ( $3.0=0.5)$. In 14 limbs, we measured the mean diameter of the branches (Table I). Several papers described in the literature show that nerve transfers of branches with considerable diameter differences and nerve fibers provide good results. Some researchers believe that 20 to 30 $\%$ reinnervation of muscle fibers is compatible with normal muscle function (Gordon et al., 1993; De Medinaceli, 1994). Jiang et al. (2007) report that axons in the proximal stump can multiply by increasing their number by 3 to 4 times. Lutz et al. (2000) demonstrated in rabbits that this axonal multiplication between donor and recipient was 1:3. Tötösy de Zepetnek et al. (1992) observed that at least $30 \%$ of the original motor neurons are required to achieve normal muscle 
strength in rats. Therefore, the donor nerve must have at least $30 \%$ of the number of axons of the receptor nerve. Other factors reinforce the justification for this nerve transfer, even if the mean diameter of the branches for PTM is $50 \%$ of the mean diameter of the PIN, for example, the muscular strength necessary for the extension of the thumb and fingers is minimal. Regarding the transfer to the radial nerve, an appropriated PTM branch was able to tensionless reach the ECRL, ECRB and PIN distal to branches for supinator muscle in all dissected limbs, even throughout full elbow and forearm range of movement (Figs. 9A and 9B). Although the nerve transfer leaves the PTM partially innervated, this anatomical study cannot ensure that the remaining branch would be enough to preserve adequate pronation of the forearm. The section of the supinator branches is advantageous because it favors the direction of the MPR axons to be destined only to the extensors of the fingers and the thumb. Tubbs et al. described similar results with 20 dissections, while performing a nerve transfer of the PTM branch to the radial nerve in the cubital fossa without tension in all cases. García-López et al. transferred 1 PTM branch to the ECRL and transferred the FCR branch to the PIN in patients with radial nerve palsy or posterior cord injury. They reported 6 cases treated with excellent functional results and with no loss of forearm pronation. Fujii et al. (2007) stated that pronation is synergic to wrist extension similarly when PTM tendon is transferred to wrist extensors. Plate et al. (2013) described a case of a 26-year-old male with an 11-month posterior cord injury treated by nerve grafting of the brachial plexus and PTM branch transfer for the PIN, with good extension function of deltoid, triceps and wrist after 3 years. Prolonged denervation due to posterior cord injury may be suitable for a combination of nerve grafting at the lesion site and distal nerve transfer. $\mathrm{Li}$ et al. performed a double nerve transfer to restore fingers flexion and extension in four patients with $\mathrm{C} 7-\mathrm{T} 1$ brachial plexus injury. The radial nerve branch to the supinator was transferred to the PIN, while the PTM median nerve branch was transferred to the AIN with straightforward and minimal dissection, with no loss of forearm pronation. They reported one case that did not recover AIN function and postulate that transferring both PTM branches may provide more axons to the receptor nerve, although loss of pronation may be a concern. Some loss of pronation was described to be better than the loss of wrist extension, since grip strength is based on this ability, and PTM weakness could be surpassed by postoperative physical therapy and muscular strengthening program (Tubbs et al.). Meanwhile, forearm pronation is important for independent activities of daily living such as feeding, dressing, writing and personal hygiene, while loss of function may difficult tasks such as opening flasks or pulling door knobs (Hsiao et al.). Compensation of pronation absence includes contralateral trunk flexion combined with arm abduction and supinated position may critically limit arm and hand function. Yang et al. described a case of PTM branch transfer to the AIN and 14 months post-operative evaluation with grade IV recovery of fingers and thumb flexion. This was based on an anatomical study of 30 limbs analyzing the mean number, length and site of origin of PTM branches.

Table II. Median nerve branches to the PTM distribution in the literature.

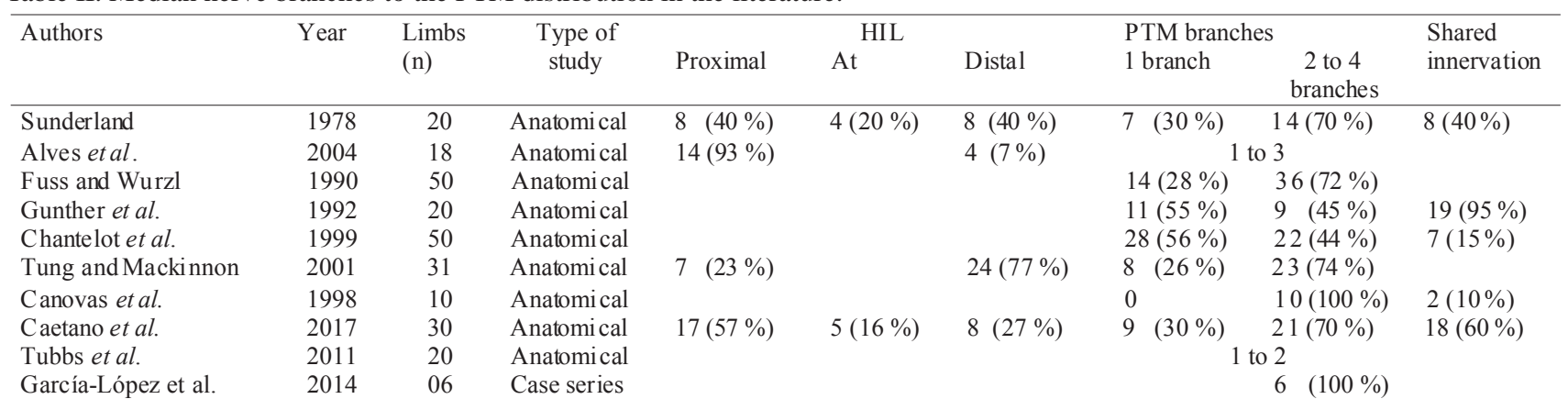

\section{CONCLUSION}

The most common anatomical pattern of PTM innervation was an exclusive supply by the median nerve with more than one branch $(70 \%)$ arising $6.8 \mathrm{~cm}$ proximal to $2.8 \mathrm{~cm}$ distal to the HIL, while the proximal branch averaged $4.0 \mathrm{~cm}$ in length and did not share innervation with other muscles. This knowledge reiterates the possibility of transferring a dispensable PTM branch for a range of recipient nerves in the forearm and prepares the surgeon for identification of intra-operatory variations. The first or second PTM branch could be transferred to the AIN, ECRB, ECRL and PIN branch in all limbs without tension and prepare the surgeon for identification of intra-operatory variations. 
ACKNOWLEDGMENTS. The authors most gratefully acknowledges the contributions and gifts of the donors and their families to medical education and scientific research, and the dedication and respect of the students toward their first patients and their patients' families.

CAETANO, E. B.; VIEIRA, L A.; SABONGI, NETO, J. J. S.; CAETANO, M. B. F.; SABONGI, R. G.; MARTINEZ, L.; OGATA, K. K. \& BONI, E. B. S. Estudio anatómico de la inervación del músculo pronador redondo y significado clínico en la transferencia nerviosa. Int. J. Morphol., 36(4):1500-1508, 2018.

RESUMEN: La relación anatómica del nervio mediano y su patrón de inervación son variables y pueden tener implicaciones directas en los procedimientos quirúrgicos, como las transferencias de los nervios distales. El objetivo de este estudio fue evaluar las variaciones anatómicas de la inervación del músculo pronador redondo (MPR) y su importancia clínica en las transferencias nerviosas. Se obtuvieron datos sobre el número de ramas del nervio mediano, el lugar de origen, la contribución con ramas de otros músculos y la posibilidad de transferir ramas prescindibles de la MPR al nervio interóseo anterior (NIA) y al nervio radial. El origen más común de las ramas fue proximal a la línea intercondilar humeral. Se identificó la presencia de una sola rama de MPR en 9 miembros superiores, de los cuales 6 fueron exclusivas para este músculo. La mayoría de los especímenes presentaron más de una rama al MPR, con dos ramas en 19 de ellos, aunque solamente 6 no compartían ramas con otros músculos. La rama proximal del MPR fue lo suficientemente larga como para ser transferida a la NIA en un total de 23 miembros superiores y ramas del nervio radial. Estas transferencias fueron posibles incluso en el antebrazo, durante la supinación y la flexiónextensión del codo. El uso de la rama MPR puede considerarse para transferencias en lesiones de raíz C7-T1 del plexo braquial, con cuidado en cuanto a la disponibilidad de múltiples ramas de MPR y tensión a la NIA y las ramas nerviosas radiales.

PALABRAS CLAVE: Traumatismos de los nervios periféricos; Transferencia de nervios; Nervio mediano; Variación anatómica.

\section{REFERENCES}

Alves, N.; Cândido, P. L. \& Frazão, R. Innervation of the pronator teres muscle. Int. J. Morphol., 22(3):237-40, 2004.

Bertelli, J. A. \& Ghizoni, M. F. Transfer of supinator motor branches to the posterior interosseous nerve in C7-T1 brachial plexus palsy. J. Neurosurg., 113(1):129-32, 2010.

Caetano, E. B.; Vieira, L. A.; Sprovieri, F. A. A.; Petta, G. C.; Nakasone, M. T. \& Serafim, B. L. C. Variações anatômicas do músculo pronador redondo e sua importância nas síndromes compressivas. Rev. Bras. Ortop., 52(2):169-75, 2017.

Canovas, F.; Mouilleron, P. \& Bonnel, F. Biometry of the muscular branches of the median nerve to the forearm. Clin. Anat., 11(4):239-45, 1998.

Chantelot, C.; Feugas, C.; Guillem, P.; Chapnikoff, D.; Rémy, F. \& Fontaine, C. Innervation of the medial epicondylar muscles: an anatomic study in 50 cases. Surg. Radiol. Anat., 21(3):165-8, 1999.

De Medinaceli, L. Cell Surgery to Repair Divided Nerves. New York, CASISCID, 1994. pp.90-101.

Fujii, H.; Kobayashi, S.; Sato, T.; Shinozaki, K. \& Naito, A. Co-contraction of the pronator teres and extensor carpi radialis during wrist extension movements in humans. J. Electromyogr. Kinesiol., 17(1):80-9, 2007.
Fuss, F. K. \& Wurzl, G. H. Median nerve entrapment. Pronator teres syndrome. Surgical anatomy and correlation with symptom patterns. Surg. Radiol. Anat., 12(4):267-71, 1990.

García-López, A.; Navarro, R.; Martinez, F. \& Rojas, A. Nerve transfers from branches to the flexor carpi radialis and pronator teres to reconstruct the radial nerve. J. Hand Surg. Am., 39(1):50-6, 2014.

Gordon, T.; Yang, J. F.; Ayer, K.; Stein, R. B. \& Tyreman, N. Recovery potential of muscle after partial denervation: a comparison between rats and humans. Brain Res. Bull., 30(3-4):477-82, 1993.

Gunther, S. F.; DiPasquale, D. \& Martin, R. The internal anatomy of the median nerve in the region of the elbow. J. Hand Surg. Am., 17(4):648-56, 1992.

Hsiao, E. C.; Fox, I. K.; Tung, T. H. \& Mackinnon, S. E. Motor nerve transfers to restore extrinsic median nerve function: case report. Hand (N. Y.), 4(1):927, 2009.

Jiang, B. G.; Yin, X. F.; Zhang, D. Y.; Fu, Z. G. \& Zhang, H. B. Maximum number of collaterals developed by one axon during peripheral nerve regeneration and the influence of that number on reinnervation effects. Eur. Neurol., 58(1):12-20, 2007.

Li, Z.; Reynolds, M.; Satteson, E.; Nazir, O.; Petit. J. \& Smith, B. P. Double distal intraneural fascicular nerve transfers for lower brachial plexus injuries. J. Hand Surg., 41(4):e15-9, 2016.

Lutz, B. S.; Chuang, D. C.; Chuang, S. S.; Hsu, J. C.; Ma, S. F. \& Wei, F. C. Nerve transfer to the median nerve using parts of the ulnar and radial nerves in the rabbit--effects on motor recovery of the median nerve and donor nerve morbidity. J. Hand Surg. Br., 25(4):329-35, 2000.

Mackinnon, S. E. \& Novak, C. B. Nerve transfers. New options for reconstruction following nerve injury. Hand Clin., 15(4):643-66, 1999.

Nebot-Cegarra, J.; Perez-Berruezo, J. \& Reina de la Torre, F. Variations of the pronator teres muscle: predispositional role to median nerve entrapment. Arch. Anat. Histol. Embryol., 74:35-45, 1991.

Paturet, G. Traité d'Anatomie Humaine. Tome 2. Paris, Masson, 1954. pp.472-7.

Pires, P. R. \& Andrade, R. P. Síndromes Compressivas no Membro Superior. In: Pardini Júnior, A. \& Freitas, A. Cirurgia da Mão: Lesões Não Traumáticas. $2^{\mathrm{a}}$ ed. Rio de Janeiro, Medbook, 2008. pp.263-97.

Plate, J. F.; Ely, L. K.; Pulley, B. R.; Smith, B. P. \& Li, Z. Combined proximal nerve graft and distal nerve transfer for a posterior cord brachial plexus injury. J. Neurosurg., 118(1):155-9, 2013.

Rouvière, H. \& Delmas, A. Anatomie Humaine. Tome 3. Paris, Masson, 1984. pp.232-3.

Sunderland, S. Nerves and Nerve Injuries. Edinburgh, Churchill Livingstone, 1978.

Tötösy de Zepetnek, J. E.; Zung, H. V.; Erdebil, S. \& Gordon, T. Innervation ratio is an important determinant of force in normal and reinnervated rat tibialis anterior muscles. J. Neurophysiol., 67(5):1385-403, 1992.

Tubbs, R. S.; Beckman, J. M.; Loukas, M.; Shoja, M. M. \& Cohen-Gadol, A. A. Median nerve branches to the pronator teres: cadaveric study with potential use in neurotization procedures to the radial nerve at the elbow. J. Neurosurg., 114(1):253-5, 2011.

Tung, T. H. \& Mackinnon, S. E. Flexor digitorum superficialis nerve transfer to restore pronation: two case reports and anatomic study. J. Hand Surg. Am., 26(6): 1065-72, 2001

Yang, J.; Jia, X.; Yu, C. \& Gu, Y. Pronator teres branch transfer to the anterior interosseous nerve for treating C8T1 brachial plexus avulsion: an anatomic study and case report. Neurosurgery, 75(4):375-9, 2014.

Corresponding author:

Prof. Dr. Edie Benedito Caetano

Department of Surgery

Pontifical Catholic University of São Paulo, Brazil.

Rua Joubert Wey, 290

18030-270, Sorocaba (SP),

BRAZIL

Email: ediecaetano@uol.com.br

Received: 10-10-2017

Accepted: 05-04-2018 